\title{
Tower Grounding Improvement Versus Line Surge Arresters: Comparison of Remedial Measures for High-BFOR Subtransmission Lines
}

\author{
Fabio Massimo Gatta, Alberto Geri, Stefano Lauria, Member, IEEE, Marco Maccioni, and Francesco Palone
}

\begin{abstract}
5 Abstract-This paper presents a technical/economic compari6 son between remedial measures aimed at improving the lightning 7 performance of an existing Italian three-phase $150-\mathrm{kV}$ overhead 8 line. The line is characterized by a very high back-flashover rate 9 (BFOR), due to large grounding resistance values. Two counter10 measures are proposed: grounding system improvement with ad11 ditional vertical rods and line metal oxide surge arrester (MOSA) 12 installation on one or all phases. A Monte Carlo ATP-EMTP 13 procedure developed by the authors, which takes into account 14 both the tower grounding nonlinear transient response due to soil 15 ionization and MOSA nonlinear response, has been applied to 16 evaluate and compare the effectiveness of the proposed counter17 measures. The installation of MOSA on all phases is technically 18 the best option, but it is relatively expensive. Tower grounding 19 improvement and MOSA installation on the lower phase yield 20 very similar BFORs: the economic comparison strongly depends 21 on tower's accessibility and soil nature.
\end{abstract}

22 Index Terms-ATP-EMTP, back-flashover rate (BFOR), 23 grounding system, high-voltage (HV) overhead line, metal oxide 24 surge arrester (MOSA), Monte Carlo method.

\section{INTRODUCTION}

26 T N Italy, 132- or 150-kV high-voltage (HV) overhead lines 28 (OHLs) form the bulk (40 $000 \mathrm{~km})$ of Terna's (the Ital29 ian transmission network operator, TSO) subtransmission net30 works, often running through hilly or mountainous terrain due 31 to the country's geography. The attendant increased exposure 32 to lightning, in conjunction with the relatively high keraunic 33 level of mainland Italy, is liable to cause undesirably high 34 back-flashover rates (BFORs). This notably applies to older 35 lines, whose tower grounding systems can be also impaired 36 by corrosion [1], sometimes leading to equivalent grounding 37 resistances in excess of $100 \Omega$. High BFORs are often asso38 ciated to a limited number of "rogue" towers, characterized

Manuscript received December 31, 2014; revised April 7, 2015; accepted June 14, 2015. Paper 2014-PSEC-0853.R1, approved for publication in the IEEE TRANSACTIONS ON Industry APpliCATIONs by the Power Systems Engineering Committee of the IEEE Industry Applications Society.

F. M. Gatta, A. Geri, S. Lauria, and M. Maccioni are with the Department of Astronautics, Electrical and Energetics Engineering (DIAEE), University of Rome "La Sapienza," 00185 Rome, Italy (e-mail: fabiomassimo.gatta@ uniroma1.it; alberto.geri@uniroma1.it; stefano.lauria@uniroma1.it; marco. maccioni@uniroma1.it).

F. Palone is with Terna Rete Italia S.p.A., 00156 Rome, Italy (e-mail: francesco.palone@terna.it).

Digital Object Identifier 10.1109/TIA.2015.2448613 by a combination of high lightning exposure (e.g., located 39 on ridges or mountainsides) and high grounding resistance. 40 A straightforward corrective measure is tower grounding im- 41 provement, which can range from total rebuilding of badly cor- 42 roded systems to more limited actions, such as the installation 43 of a few (2-4) additional rods alongside the existing grounding 44 system. In recent years, lightweight polymer-insulated metal 45 oxide surge arresters (MOSAs), so-called "line arresters," have 46 been installed on OHL towers directly across phase insulation 47 [2]-[4]. In Italy, where tower grounding improvement often 48 incurs serious delays due to the legal/regulatory framework 49 (authorization and property expropriation problems), the instal- 50 lation of surge arresters meets less obstacles under this regard 51 and can constitute an alternative solution to the rogue towers 52 problem.

This paper presents a technical-economic comparison of the 54 aforementioned BFOR countermeasures for an existing $150-\mathrm{kV} 55$ subtransmission OHL operated by Terna in Center Italy. The 56 10.8-km-long line crosses a mountain ridge with a moderate 57 keraunic level ( 3.5 flashes $/ \mathrm{km}^{2} /$ year) for Italy, whereas soil re- 58 sistivity is about $1000 \Omega \cdot \mathrm{m}$; furthermore, grounding resistance 59 has substantially increased at some towers due to corrosion of 60 earth electrodes. All these factors contribute to an exceptionally 61 high BFOR recorded by the TSO (about 70 faults $/ 100 \mathrm{~km} / \mathrm{year}$ ). 62

Both applicable countermeasures, that is, grounding system 63 improvement with additional vertical rods and line arrester 64 installation on one or more phases, are investigated by means of 65 ATP-EMTP transient simulations. The impact of line arresters 66 on the lightning performance of OHLs has been the object of 67 several papers: deterministic studies, basically focused on ar- 68 rester location and using ATP-EMTP transient simulations, are 69 presented in [5] and [6]. A mixed Monte-Carlo-deterministic 70 procedure was proposed in [7], whereas a probabilistic ap- 71 proach (not using Monte Carlo method) is detailed in [8], 72 in order to evaluate the failure risk of surge arresters caused 73 by lightning flash. Despite different approaches, all aforemen- 74 tioned studies point out to the highly beneficial role played by 75 line arresters (whose systematic installation can reduce or even 76 nullify the BFOR), as well as discussing the effectiveness of 77 partial protection by line surge arrester (only one phase per 78 tower and/or only some towers). In this paper, the lightning 79 performance of the line, in the starting configuration and after 80 the implementation of either of the proposed countermeasures, 81 is evaluated by means of a Monte Carlo ATP-EMTP procedure 82 [9], [10] developed by the authors and able, in addition to 83 


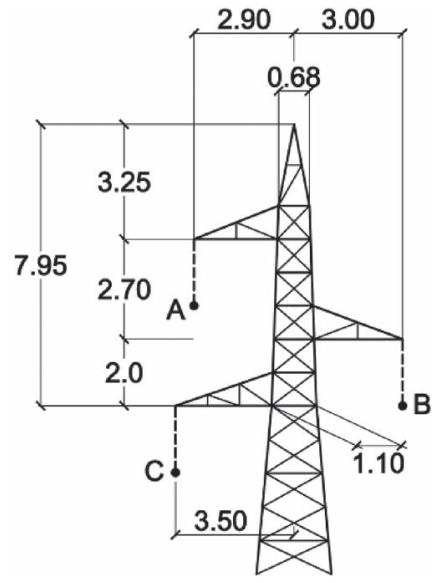

Fig. 1. Outline of the OHL tower head (dimensions are in meters).

TABLE I

Phase AND SHIEld WiRe CONDUCtor CoORdinAtes

\begin{tabular}{|c|c|c|c|c|}
\hline & A & B & C & SW \\
\hline $\mathbf{x}(\mathbf{m})$ & -2.9 & 3 & -3.5 & 0 \\
\hline $\mathbf{y}(\mathbf{m})$ & 22.1 & 20.1 & 18.1 & 27.7 \\
\hline
\end{tabular}

84 previous contributions, to provide a statistical assessment of 85 MOSA failure rates. Detailed modeling of line insulation, tower 86 grounding nonlinear transient response due to soil ionization, 87 and MOSAs, where present, is included. Results obtained are 88 finally analyzed and compared, both from a technical and from 89 an economic point of view.

\section{System Modeling Details}

\section{A. OHL Model}

92 The single-circuit three-phase $150-\mathrm{kV} 50-\mathrm{Hz}$ OHL under 93 study is $10.8 \mathrm{~km}$ long (37 line spans, for an average 290-m 94 span length), with a single $11.5-\mathrm{mm}$ steel ground wire and the 95 phases, equipped with single $31.5-\mathrm{mm}$ aluminium conductor

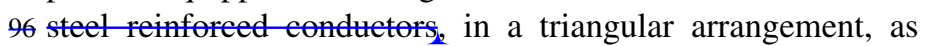
97 shown in Fig. 1. The simulated tower height is $27.7 \mathrm{~m}$ (the av98 erage tower height of the 38 towers), with an $11.4-\mathrm{m}$ phase con99 ductor sag and a 9.7-m shield wire sag. Table I reports the phase 100 and shield wire conductors coordinates. All line spans were 101 simulated in ATP-EMTP by means of the "JMarti" frequency102 dependent model (reference frequency for modal calculation 103 taken at $500 \mathrm{kHz}$ ). At both ends of the simulated line stretch, 104 the OHL model is connected to the line surge impedances: 105 phase conductors are then terminated on a three-phase $150-\mathrm{kV}$ $10650-\mathrm{Hz}$ voltage system, with one of the phases always at the 107 maximum operating voltage to ground (i.e., $170 \cdot \sqrt{ } 2 / \sqrt{ } 3 \mathrm{kV}$ ), 108 whereas the shield wire is solidly grounded. Segments and 109 crossarms of the OHL towers have been simulated by means of 110 lossless single-phase transmission lines (Bergeron model, with $111 Z_{T}=200 \Omega$ ); at each tower, the shield wire is connected to the 112 tower peak. Corona effect was not simulated.

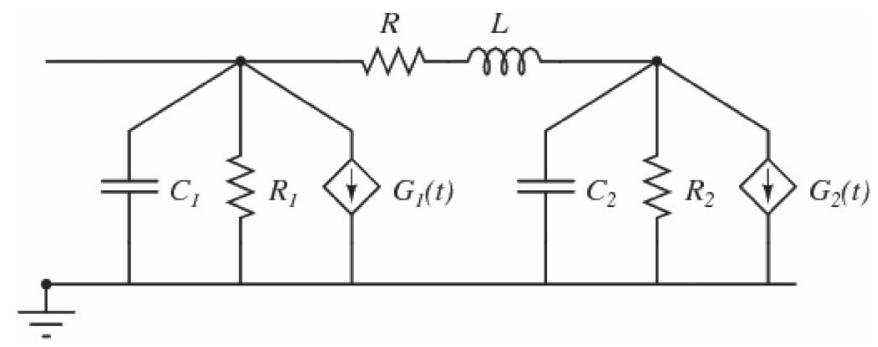

Fig. 2. Simplified pi-circuit model of tower grounding system [7]-[9].

\section{B. Line Insulation Model}

Line insulation breakdown has been simulated with the 114 CIGRE Leader Progression Model, implemented with ATP- 115 EMTP by means of the embedded "MODELS" program- 116 ming/simulation language, i.e.,

$$
\frac{d l}{d t}=k \cdot u(t)\left[\frac{u(t)}{d_{G}-l(t)}-E_{0}\right]
$$

where $l(t)(\mathrm{m})$ is the leader length, $d_{G}(\mathrm{~m})$ is the gap length, 118 and $u(t)(\mathrm{kV})$ is the voltage across the gap. $E_{0}(\mathrm{kV} / \mathrm{m})$ and 119 $k\left(\mathrm{~m}^{2} \cdot \mathrm{kV}^{-2} \cdot \mathrm{s}^{-1}\right)$ depend on gap configuration and impulse 120 polarity. The gap length $d_{G}$ is $1.46 \mathrm{~m}$.

\section{Lightning Model}

The well-known "Heidler" impulse current source available 123 in ATP-EMTP has been used in all simulations, i.e.,

$$
i(t)=\frac{I_{P}}{\eta} \cdot \frac{k_{s}^{n}}{1+k_{s}^{n}} \cdot e^{-\frac{t}{\tau_{2}}}
$$

where $I_{P}$ is the peak current; $\eta$ is the correction factor of 125 the peak current; $k_{s}=t / \tau_{1} ; \tau_{1}$ and $\tau_{2}$ are time constants 126 determining current rise time and decay time, respectively; and 127 $n$ is the current steepness factor.

\section{Grounding System Model}

The transient simulation of tower grounding systems is car- 130 ried out by means of the simplified pi-circuit model proposed 131 by the authors in [11]-[13] and depicted in Fig. 2.

The pi-circuit model is obtained by synthesis of a full cir- 133 cuit model [14], able to reproduce the transient impedance of 134 extended grounding systems also taking into account the soil 135 ionization. The linear components of the pi circuit (shunt resis- 136 tors and capacitors $R_{1}, R_{2}, C_{1}$, and $C_{2}$; longitudinal resistor 137 and inductance $R$ and $L$ ) are estimated by comparing the input 138 impedances of the full circuit model (ATP-EMTP frequency 139 scans without considering ionization) and of the pi circuit, 140 switching off the ideal voltage-controlled current sources $G_{1} 141$ and $G_{2}$. A $\mu$ GA-based [15] optimization procedure minimizes 142 the standard deviation between the input impedances in the fre- 143 quency range $1 \mathrm{~Hz}$ to $1 \mathrm{MHz}$. Ideal voltage-controlled current 144 sources $G_{1}$ and $G_{2}$ simulate nonlinear soil ionization caused 145 

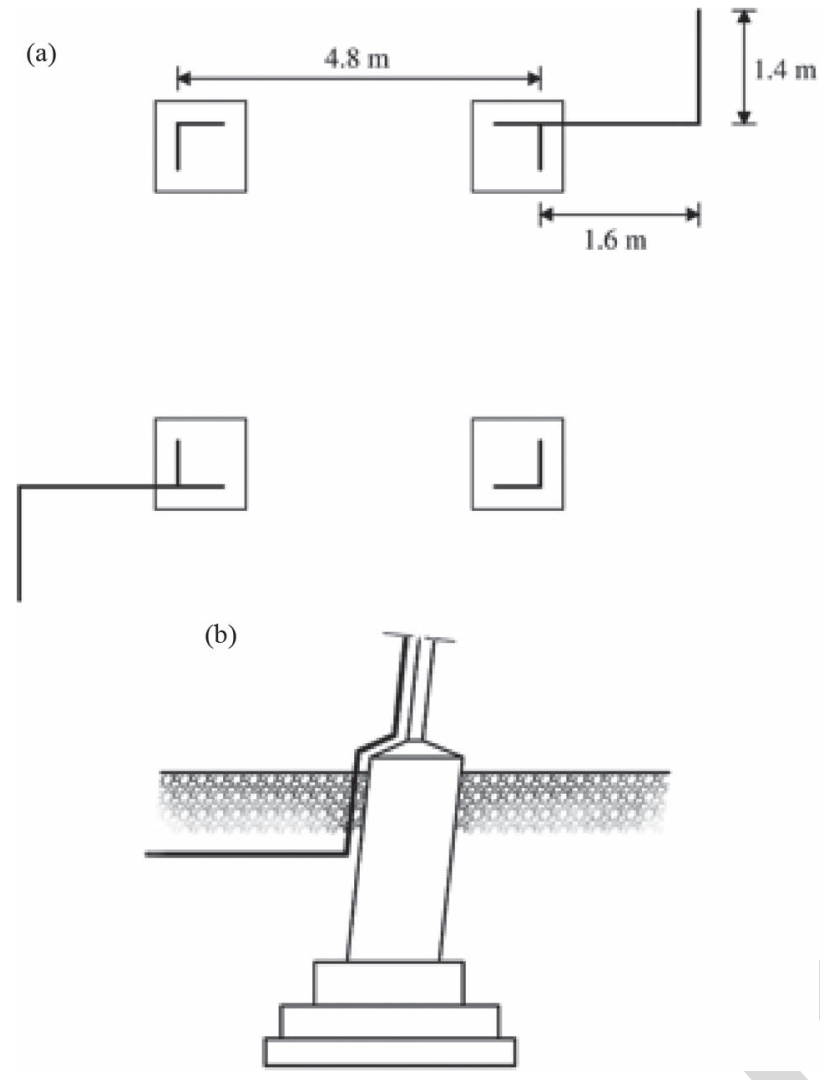

Fig. 3. (a) Sketch of the MT1 grounding system. (b) Connection at the tower foot (burying depth $0.8 \mathrm{~m}$ ).

146 by large current pulses. The analytical functions assigned to $G_{1}$ 147 and $G_{2}$ are $(i=1,2)$

$$
G_{i}(t)=\frac{V_{R i}(t)}{F_{i}(t)}-\frac{V_{R i}(t)}{R_{i}}
$$

148 being $V_{R i}(t)$ the instantaneous value of the voltage across the 149 linear shunt resistor $R_{i}$, and $F_{i}(t)$ is given by

$$
F_{i}(t)=R_{i}-\alpha_{i} \cdot \log \left(10^{-4}+\beta_{i} \frac{V_{R_{i}}(t)}{R_{i}}\right), \quad F_{i} \in\left[10^{-4} ; R_{i}\right]
$$

150 where $\alpha_{i}$ (expressed in ohms) and $\beta_{i}$ (expressed in $\mathrm{A}^{-1}$ ) 151 take into account nonlinear soil ionization phenomena. The pi152 circuit model is implemented with ATP-EMTP by means of the 153 "MODELS" programming language [16].

154 Thirty-five out of 38 towers of the line under study are 155 equipped with the simplest Terna's standard tower ground156 ing system, code-named MT1 and depicted in Fig. 3. The 157 low-frequency ground resistance value of the simulated MT1 158 grounding system is $114 \Omega$ (considering a constant $1000-\Omega \cdot \mathrm{m}$ 159 soil resistivity value along the whole line), which is in accor160 dance with ground resistance values measured at $50 \mathrm{~Hz}$ by 161 the TSO, ranging from 50 to $125 \Omega$. At the remaining three 162 towers, the measured ground resistance at $50 \mathrm{~Hz}$ is about $500 \Omega$ : 163 such a large value is very probably due to corrosion of the 164 original grounding system. In the simulations, a 2-m-long ver165 tical rod (1ROD in the following), with a low-frequency ground 166 resistance value around $500 \Omega$, is used.
TABLE II

Linear PARAMETER VALUES For Pi-TYPe SIMPLIFIEd EQUIVALENT CIRCUITS

\begin{tabular}{|c|c|c|c|c|c|c|}
\hline & $\begin{array}{c}\boldsymbol{R}_{\mathbf{1}} \\
(\boldsymbol{\Omega})\end{array}$ & $\begin{array}{c}\boldsymbol{R}_{\mathbf{2}} \\
(\boldsymbol{\Omega})\end{array}$ & $\begin{array}{c}\boldsymbol{R} \\
(\boldsymbol{\Omega})\end{array}$ & $\begin{array}{c}\boldsymbol{L} \\
(\boldsymbol{\mu} \mathbf{H})\end{array}$ & $\begin{array}{c}\boldsymbol{C}_{\mathbf{1}} \\
(\mathbf{n F})\end{array}$ & $\begin{array}{c}\boldsymbol{C}_{\mathbf{2}} \\
(\mathbf{n F})\end{array}$ \\
\hline MT1 & 386.8 & 8.2 & 153.9 & 1.0 & 2.74 & 1.00 \\
\hline 1ROD & 928.9 & 119.9 & 972.6 & 0.48 & 0.09 & 0.79 \\
\hline 4RODS $\| \mathbf{1 R O D}$ & 96.2 & 25.6 & 196.9 & 3.9 & 4.70 & 0.33 \\
\hline 4RODS|MT1 & 60.2 & 748.9 & 5.1 & 25.0 & 4.97 & 0.57 \\
\hline
\end{tabular}

TABLE III

NONLINEAR COEFFICIENT VALUES FOR Pi-TYPE SIMPLIFIEd EQUIVALENT CIRCUITS

\begin{tabular}{|c|c|c|c|c|}
\hline & $\begin{array}{c}\alpha_{1} \\
(\Omega)\end{array}$ & $\begin{array}{c}\alpha_{2} \\
(\boldsymbol{\Omega})\end{array}$ & $\begin{array}{c}\beta_{1} \\
\left(\mathbf{A}^{-1}\right)\end{array}$ & $\begin{array}{c}\beta_{2} \\
\left(\mathbf{A}^{-1}\right)\end{array}$ \\
\hline MT1 & 27.08 & 0 & 48.08 & 1.50 \\
\hline 1ROD & 44.00 & 20.00 & 4010.6 & 8500.5 \\
\hline 4RODS $\|$ 1ROD & 2.96 & 2.91 & 4010.6 & 8500.5 \\
\hline 4RODS $\|$ MT1 & 1.41 & 0.91 & 3950.2 & 7458.5 \\
\hline
\end{tabular}

As reported in Section I, one of the foreseeable counter- 167 measures aimed at improving the grounding system behavior 168 is the addition of vertical rods: in this paper, four vertical 169 rods, each $5 \mathrm{~m}$ long and connected to one tower foot, are 170 simulated (Countermeasure 1 in the following). The addition 171 of four vertical rods to the preexisting MT1 grounding system 172 (4RODS $\|$ MT1 in the following) decreases the low-frequency 173 ground resistance value from $114 \Omega$ to about $56 \Omega$, whereas the 174 same addition to 1 ROD configuration (4RODS $\| 1$ ROD in the 175 following) causes a very large ground resistance decrease from 176 500 to $67 \Omega$.

Numerical values of the pi-circuit parameters used to simu- 178 late the above-described grounding system configurations are 179 reported in Tables II and III.

\section{E. MOSA Model}

MOSAs have been simulated with the model described in 182 [17] and depicted in Fig. 4, consisting of a constant resistance 183 $R=1 \mathrm{~m} \Omega$, two nonlinear resistors $A_{0}$ and $A_{1}$, whose $V-I 184$ characteristics (both of the form $I=B V^{q}$ ) are determined 185 by the parameters listed in Table IV, and the inductances 186 $L_{0}$ and $L_{1}$ defined by the following equations (values are in 187 microhenries):

$$
\begin{aligned}
& L_{0}=\frac{1}{12} \cdot \frac{V_{r 1 / T_{2}}-V_{r 8 / 20}}{V_{r 8 / 20}} \cdot V_{n} \\
& L_{1}=\frac{1}{4} \cdot \frac{V_{r 1 / T_{2}}-V_{r 8 / 20}}{V_{r 8 / 20}} \cdot V_{n}
\end{aligned}
$$

where $V_{n}$ is the arrester rated voltage, $V_{r 1 / T 2}$ is the residual 189 voltage for a 10-kA fast front current surge $\left(1 / T_{2} \mu \mathrm{s}\right)$, and 190 


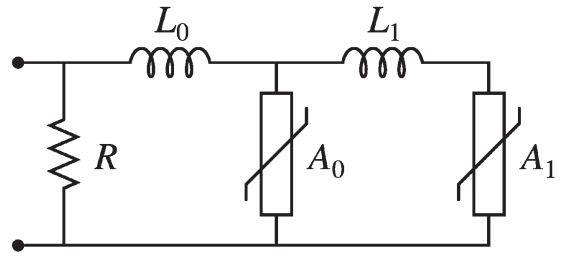

Fig. 4. MOSA model used in simulations [13].

TABLE IV

$V-I$ Characteristics FOR $A_{0}$ AND $A_{1}$ (VAlues ARE IN P.U. OF THE $V_{R 8 / 20}$ Voltage)

\begin{tabular}{|c|c|c|}
\hline $\begin{array}{c}I \\
(\mathbf{k A})\end{array}$ & $\begin{array}{c}\boldsymbol{A}_{\mathbf{0}} \\
\text { (p.u.) }\end{array}$ & $\begin{array}{c}\boldsymbol{A}_{\mathbf{1}} \\
\text { (p.u.) }\end{array}$ \\
\hline $2 \cdot 10^{-6}$ & 0.810 & 0.623 \\
\hline 0.1 & 0.974 & 0.788 \\
\hline 1 & 1.052 & 0.866 \\
\hline 3 & 1.108 & 0.922 \\
\hline 10 & 1.195 & 1.009 \\
\hline 20 & 1.277 & 1.091 \\
\hline
\end{tabular}

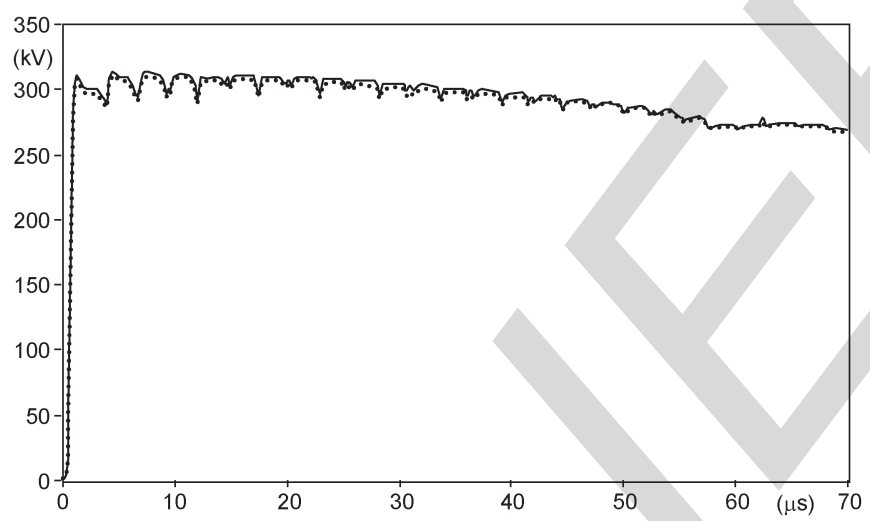

Fig. 5. Residual voltage calculated by ATP-EMTP for a 100-kA 1.46-/390- $\mu \mathrm{s}$ direct stroke. (Continuous line) MOSA simulated by true nonlinear resistance. (Dotted line) MOSA simulated by piecewise-linear resistance.

$191 V_{r 8 / 20}$ is the residual voltage for a 10-kA current surge with 192 an $8-120-\mu$ s shape. The model is derived from the one rec193 ommended by the IEEE W.G. 3.4.11 [18], but parameters are 194 directly calculated by using the standard data reported in the ar195 rester data sheets, and any iterative procedure in order to correct 196 parameter values is needed. The model has been validated by 197 comparison between the calculated residual voltages and those 198 reported on manufacturer's data sheet [17] and by experimental 199 tests [19].

200 The ATP-EMTP implementation of the model may be per201 formed by using Type-92 branch cards [16], either the so-called 202 true nonlinear exponential MOSA $R(i)$ or the piecewise-linear 203 resistance $R(i)$. Fig. 5 reports the residual voltages calculated 204 by ATP-EMTP, simulating a direct lightning (100-kA Heidler 205 source) on a $150-\mathrm{kV}$ OHL tower equipped with MOSAs on all phases, by using the two different Type-92 implementa- 206 tions: a very good agreement is obtained. In our Monte Carlo 207 simulations, however, the piecewise-linear resistance Type-92 208 has been implemented, in order to avoid numerical oscillations 209 observed in our complete OHL ATP-EMTP model if MOSAs 210 are simulated with true nonlinear resistance and very large 211 lightning strokes (peak current greater than $200 \mathrm{kA}$ ) hit the line. 212

In this paper, the installation of MOSAs along the whole 213 OHL under study is proposed (Countermeasure 2 in the fol- 214 lowing). In the simulations described in Section IV, MOSAs 215 are installed on each phase of the OHL ("MOSA-ABC" con- 216 figuration) or only on one phase ("MOSA-A", "MOSA-B," 217 and "MOSA-C" configurations, respectively). The simulated 218 line arrester manufacturer's data are as follows: arrester rated 219 voltage $U_{r}=138 \mathrm{kV}, V_{r 1 / T 2}=327 \mathrm{kV}, V_{r 8 / 20}=313 \mathrm{kV}, 220$ yielding $L_{0}=0.527 \mu \mathrm{H}$ and $L_{1}=1.58 \mu \mathrm{H}$; the MOSA's ther- 221 mal energy rating $W_{\text {th }}[20]$ is $345 \mathrm{~kJ}$.

\section{BFOR CAlculation Procedure}

The BFOR is evaluated by means of a Monte Carlo proce- 224 dure. A large population of $N_{\text {tot }}$ lightnings, assumed to fall 225 within a 1-km-wide swath centered on the OHL, is generated; 226 only strokes to tower are considered, and among these, the 227 sample of $N_{\text {Lin }}$ flashes that actually hit the line is extracted 228 by means of the Eriksson electrogeometric model [21]. The 229 attendant strokes are simulated by means of an ATP-EMTP 230 system model, in order to investigate the occurrence of back 231 flashover: $N_{\mathrm{BFO}}$ total flashovers are then yielded out of $N 232$ strokes. At the end of the procedure, when $N=N_{\text {tot }}$, the 233 BFOR (referred to $100 \mathrm{~km}$ of tine year) is then calculated as

$$
\mathrm{BFOR}=k_{\mathrm{BFO}} \cdot \frac{N_{\mathrm{BFO}}}{N_{\mathrm{tot}}} \cdot N_{g} \cdot 100
$$

where $N_{g}$ is the ground flash density (flashes $/ \mathrm{km}^{2} /$ year), and 235 $k_{\mathrm{BFO}}$ is a numerical multiplicative coefficient taking into ac- 236 count the percentage of the $N_{\text {Lin }}$ lightning strokes, which are 237 able to cause back flashover. In previous papers by the authors 238 [9], [10], $k_{\mathrm{BFO}}$ was set equal to 0.6 , since strokes to the shield 239 wire (40\% of the total, according to [22]) were disregarded, 240 i.e., it is assumed that only strokes to tower are liable to cause 241 back flashover. In the OHL under study, this assumption is 242 not correct, due to the very high values of tower grounding 243 resistance found along the line; thus, an approach able to 244 roughly estimate $k_{\mathrm{BFO}}$ has been developed by the authors. 245

1) Evaluate the minimum peak current $I_{\mathrm{Pmin}}$ out of $N_{\mathrm{BFO}} 247$ lightning strokes, liable to cause back flashover. 248

2) For strokes to the shield wire, the minimum current liable 249 to cause back flashover, i.e., $I_{\mathrm{Pmin}}(l)$, may be evaluated, 250 disregarding the surge attenuation along the span, as lin- 251 early increasing from $I_{\mathrm{Pmin}}$ (stroke to tower) to $2 \cdot I_{\mathrm{P} \min } 252$ (stroke to midspan).

3) Evaluate the probability $p_{\mathrm{sw}}(l)$ that a lightning stroke 254 having $I_{P}$ greater or equal to $I_{\mathrm{Pmin}}(l)$ hit the shield wire 255 at the distance $l$ from the tower. 
TABLE $\mathrm{V}$

STATISTICAL PARAMETERS OF LightNing CURRENT (First Negative ANd Positive Return Strokes)

\begin{tabular}{|c|c|c|c|c|}
\hline \multirow{2}{*}{ Parameter } & \multicolumn{2}{|c|}{ Median value } & \multicolumn{2}{c|}{ Standard deviation } \\
\cline { 2 - 5 } & + & - & + & - \\
\hline $\boldsymbol{I}_{\boldsymbol{P}}$ & $35 \mathrm{kA}$ & $31.1 \mathrm{kA}$ & 1.21 & 0.48 \\
\hline $\boldsymbol{t}_{\boldsymbol{F}}$ & $22 \mu \mathrm{s}$ & $3.83 \mu \mathrm{s}$ & 1.23 & 0.55 \\
\hline $\boldsymbol{t}_{\boldsymbol{T}}$ & $230 \mu \mathrm{s}$ & $77.5 \mu \mathrm{s}$ & 1.33 & 0.58 \\
\hline
\end{tabular}

TABLE VI

STATISTICAL PARAMETERS FOR LINE INSULATION

\begin{tabular}{|c|c|c|}
\hline Polarity & $\begin{array}{c}\text { Median value } \\
(\mathbf{k V} / \mathbf{m})\end{array}$ & $\begin{array}{c}\text { Standard deviation } \\
(\mathbf{k V} / \mathbf{m})\end{array}$ \\
\hline+ & 560 & 16.80 \\
\hline- & 605 & 18.15 \\
\hline
\end{tabular}

257

258

259

260

261 The description of the statistical inputs is given in the follow262 ing subsections.

\section{A. Lightning Polarity}

264 Assuming that $90 \%$ of flashes to ground are negative [23], 265 lightning polarity is associated to a random variable uniformly 266 distributed between 0 and 1 : if the random number exceeds 0.9 , 267 the flash is positive; otherwise, it is negative.

\section{B. Lightning Stroke Parameters}

269 The statistical variation of lightning stroke parameters (peak 270 current $I_{P}$, front time $t_{F}$, and tail time $t_{T}$ ) has been assumed to 271 follow a log-normal distribution. According to [23], values of 272 medians and standard deviations, both for positive $(+)$ and first 273 negative (-) strokes, are reported in Table V.

\section{C. Line Insulation Parameters}

275 Statistical data for the critical field $E_{0}$ in (1), i.e., median 276 value $E_{0 m}$ and standard deviation, are taken from [24] and 277 summarized in Table VI. Values of constant $k$ in (1) are $2781.2 \cdot 10^{-6}$ and $1.3 \cdot 10^{-6}$ for positive and negative polarities, 279 respectively [23].

\section{D. Phase Angle of the Supply Voltage}

281 The phase angle of the three-phase positive phase sequence 282 system of impressed voltages is assumed as a uniformly dis283 tributed variable between $0 \%$ and $360 \%$.

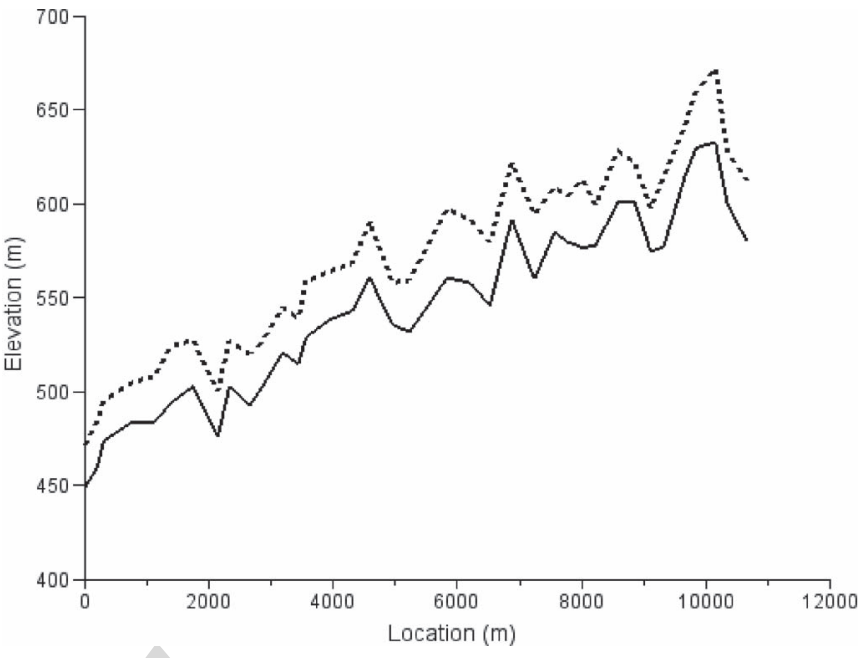

Fig. 6. (Continuous line) Ground-level height profile along the OHL. (Dotted line) Shield wire height.

\section{E. Lightning Location}

To check the occurrence of a lightning stroke to the OHL, 285 the position of the lightning in a 1-km-wide strip, centered on 286 the OHL (implicitly, its initial distance from the line, assum- 287 ing a vertical channel), is generated as a random uniformly 288 distributed variable, according to [25]. From the peak current 289 value of the given lightning stroke, the attractive radius $R_{a}$ of 290 the OHL, according to Eriksson's electrogeometric model [21], 291 is calculated as

$$
R_{a}=0.67 \cdot H^{0.6} \cdot I_{P}^{0.74}
$$

$H$ being the tower height (m), and $I_{P}$ the peak current 293 (kA): if the initial lightning position falls within the attractive 294 radius of the line, then the sampled lightning is assumed to hit 295 the OHL.

Equation (8) strictly applies to OHLs on flat terrain, which is 297 not the case of the OHL under study (the line is built on hills, 298 with the altitude profile shown in Fig. 6). In order to adapt (8) 299 to an OHL not built on a flat terrain, the following simplifying 300 assumption has been assumed: the line is considered on flat 301 terrain, and the tower height is given by the average altitude 302 of the OHL $(572.27 \mathrm{~m})$ minus the hill height at the abscissa 303 $x=0 \mathrm{~m}(449 \mathrm{~m})$, thus yielding $H=132.27 \mathrm{~m}$.

\section{RESUlTS}

The OHL length is $L=10.8 \mathrm{~km}$, of which $L_{1}=10.2 \mathrm{~km} 306$ (Stretch 1, 94.4\% of the OHL length) is equipped with the MT1 307 grounding system configuration, and $L_{2}=0.6 \mathrm{~km}$ (Stretch 2, 308 $5.6 \%$ of the OHL length) is equipped with the 1ROD grounding 309 system configuration. The BFOR of the line, experienced by 310 the TSO, is about 70 faults $/ 100 \mathrm{~km} /$ year, being $N_{g}=3.5311$ flashes $/ \mathrm{km}^{2} /$ year. In order to evaluate the BFOR related to 312 each stretch of the OHL, the Monte Carlo procedure generated 313 $N_{\text {tot }}=314254$ lightnings, corresponding to $N_{\text {Lin }}=100000314$ strokes to tower. 


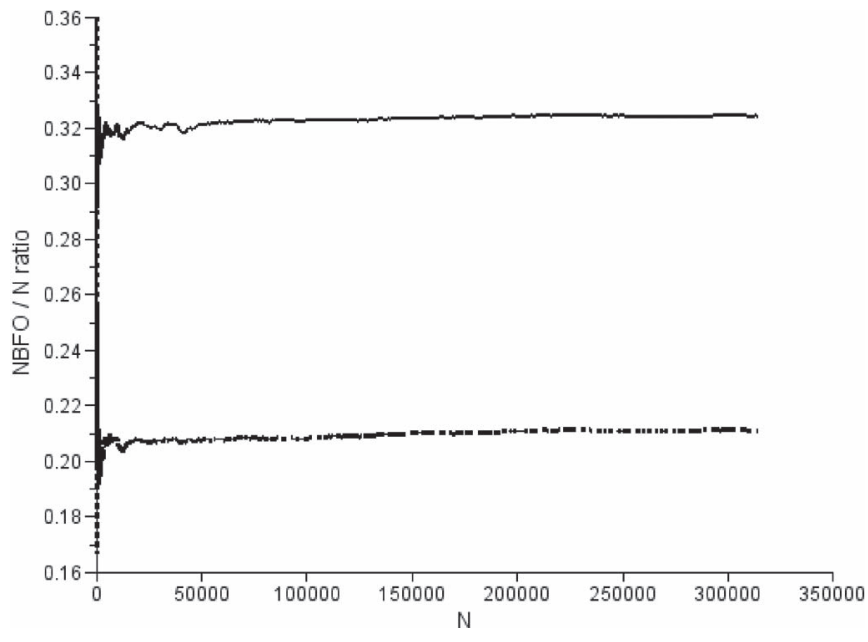

Fig. 7. Monte Carlo procedure $N_{\mathrm{BFO}} / N$ ratio versus $N$ calculated for the base case configuration. (Dotted line) Stretch 1 (with MT1 grounding system). (Continuous line) Stretch 2 (with 1ROD grounding system).

BFor Values Compu 2 BLE VII

\begin{tabular}{|c|c|c|c|}
\hline & $\boldsymbol{k}_{\text {BFO }}$ & $N_{\text {BFO }} / N_{\text {tot }}$ & $\begin{array}{c}\text { BFOR } \\
\text { (faults/100 km-year) }\end{array}$ \\
\hline Stretch 1 & 0.825 & 0.2112 & 57.600 \\
\hline Stretch 2 & 0.986 & 0.3243 & 6.216 \\
\hline
\end{tabular}

316 The procedure runs in parallel on a $12 \mathrm{CPU}$ cluster: the 317 computation time of a single ATP-EMTP lightning stroke sim318 ulation is small (about 3 s), thus obtaining, for the 100000 319 strokes to tower, a total computation time of about $7 \mathrm{~h}$.

\section{A. Base Case Configuration}

321 Fig. 7 shows the plot of the $N_{\mathrm{BFO}} / N$ ratio versus $N$ for 322 each stretch of the OHL, whereas Table VII reports the corre323 sponding BFORs evaluated by the Monte Carlo procedure. The 324 overall BFOR is therefore about 63.8 faults/100 km/year, which 325 is very close to the exact BFOR of the OHL (the procedure 326 underestimates the BFOR by about $8.9 \%$ ). This result thus 327 confirms the effectiveness of the procedure and the approxima328 tions discussed and assumed in Section III in order to simulate 329 the studied OHL. Moreover, this also shows that, despite the 330 prominently higher $N_{\mathrm{BFO}} / N$ ratio of Stretch 2, the BFOR of 331 the studied OHL is strongly dependent on the lightning perfor332 mance of Stretch 1, which is very much longer than Stretch 2.

\section{B. Countermeasure 1}

334 As described in Section II-D, Countermeasure 1 consists in 335 the addition of four vertical rods, each $5 \mathrm{~m}$ long and connected 336 to one tower foot, to all preexisting tower grounding systems. 337 This solution has been chosen because of its effectiveness in 338 decreasing the low frequency values of grounding resistance, as 339 well as for its simplicity both from a technical (civil works are 340 not long and difficult) and from a legal/regulatory (there is no 341 need for expropriations or widening the right of way) point of
TABLE VIII

BFOR VALUes COMPUTED FOR COUNTERMEASURE 1

\begin{tabular}{|c|c|c|c|}
\hline & $\boldsymbol{k}_{\text {BFO }}$ & $N_{\text {BFO }} / N_{\text {tot }}$ & $\begin{array}{c}\text { BFOR } \\
\text { (faults/100 km-year) }\end{array}$ \\
\hline $\begin{array}{c}\text { Stretch 1 } \\
\text { (4RODS } \| \text { MT1) }\end{array}$ & 0.665 & 0.1334 & 29.339 \\
\hline $\begin{array}{c}\text { Stretch 2 } \\
\text { (4RODS } \| \text { 1ROD) }\end{array}$ & 0.746 & 0.1549 & 2.244 \\
\hline
\end{tabular}

TABLE IX

BFOR VALUES COMPUTED FOR COUNTERMEASURE 2 (MOSA-ABC CONFIGURATION)

\begin{tabular}{|c|c|c|c|}
\hline & $\boldsymbol{k}_{\text {BFO }}$ & $N_{\text {BFO }} / \mathbf{N}_{\text {tot }}$ & $\begin{array}{c}\text { BFOR } \\
\text { (faults/100 km-year) }\end{array}$ \\
\hline $\begin{array}{c}\text { Stretch 1 } \\
\text { (MOSA-ABC) }\end{array}$ & 0.6 & 0.0 & 0.0 \\
\hline $\begin{array}{c}\text { Stretch 2 } \\
\text { (MOSA-ABC) }\end{array}$ & 0.6 & 0.0 & 0.0 \\
\hline
\end{tabular}

TABLE $X$

MOSAFR VALUES COMPUTED FOR COUNTERMEASURE 2 (MOSA-ABC CONFIGURATION)

\begin{tabular}{|c|c|c|c|}
\hline & $k_{\text {MOSAF }}$ & $N_{\text {MOSAF }} / N_{\text {tot }}$ & $\begin{array}{c}\text { MOSAFR } \\
\text { (failures/100 km-year) }\end{array}$ \\
\hline $\begin{array}{c}\text { Stretch 1 } \\
\text { (MOSA-ABC) }\end{array}$ & 0.6 & 0.175 & 0.347 \\
\hline $\begin{array}{c}\text { Stretch 2 } \\
\text { (MOSA-ABC) }\end{array}$ & 0.6 & 0.504 & 0.059 \\
\hline
\end{tabular}

view. Table VIII reports BFORs calculated by the Monte Carlo 342 procedure for the two stretches of the OHL, yielding an overall 343 BFOR of about 31.58 faults/100 km/year.

This result shows that Countermeasure 1 improves the light- 345 ning performance of the line and causes a $50.5 \%$ overall re- 346 duction in the BFOR; the reduction is a little more marked in 347 Stretch 2 (about 63.9\%) than in Stretch 1 (about 49.1\%).

\section{Countermeasure 2}

As described in Section II-E, Countermeasure 2 consists 350 in the installation of MOSAs on all OHL towers, directly 351 across phase insulation. The Monte Carlo procedure also al- 352 lows estimating the MOSA failure rate (here abbreviated as 353 MOSAFR, expressed in failures $/ 100 \mathrm{~km} /$ year) caused by an 354 energy absorption exceeding the rated value $W_{\mathrm{th}}=345 \mathrm{~kJ}$. The 355 calculation is performed by replacing in (7) $k_{\mathrm{BFO}}$ with $k_{\mathrm{MOSAF}} 356$ (the percentage of the $N_{\text {Lin }}$ lightnings that may cause MOSA 357 failures) and $N_{\mathrm{BFO}}$ with $N_{\mathrm{MOSAF}}$ (number of MOSA failures). 358 At first, the MOSA-ABC configuration (MOSAs installed on 359 all phases) has been evaluated: Tables IX and $\mathrm{X}$ report the 360 BFORs and MOSAFRs, estimated for each stretch of the line, 361 respectively. As expected, the overall BFOR of the OHL be- 362 comes nil, whereas the overall estimated MOSAFR amounts to 363 about 0.406 failures $/ 100 \mathrm{~km} /$ year, i.e., about 0.044 failures/year 364 (a MOSA failure every 22.7 years) in the studied OHL. Finally, 365 
TABLE XI

BFOR VALUES COMPUTED FOR COUNTERMEASURE 2 (MOSA-A, MOSA-B, AND MOSA-C CONFIGURATIONS)

\begin{tabular}{|c|c|c|c|}
\hline & $k_{\text {BFO }}$ & $N_{\text {BFO }} / N_{\text {tot }}$ & $\begin{array}{c}\text { BFOR } \\
\text { (faults/100 km-year) }\end{array}$ \\
\hline $\begin{array}{c}\text { Stretch 1 } \\
(\text { MOSA-A) }\end{array}$ & 0.762 & 0.1302 & 32.798 \\
\hline $\begin{array}{c}\text { Stretch 2 } \\
\text { (MOSA-A) }\end{array}$ & 0.982 & 0.3418 & 6.526 \\
\hline $\begin{array}{c}\text { Stretch 1 } \\
\text { (MOSA-B) }\end{array}$ & 0.762 & 0.1299 & 32.717 \\
\hline $\begin{array}{c}\text { Stretch 2 } \\
(\text { MOSA-B) }\end{array}$ & 0.982 & 0.3410 & 6.511 \\
\hline $\begin{array}{c}\text { Stretch 1 } \\
\text { MOSA-C) }\end{array}$ & 0.751 & 0.1147 & 28.463 \\
\hline $\begin{array}{c}\text { Stretch 2 } \\
(\text { MOSA-C) }\end{array}$ & 0.980 & 0.3011 & 5.730 \\
\hline
\end{tabular}

TABLE XII

MOSAFR VALUES COMPUTED FOR COUNTERMEASURE 2 (MOSA-A, MOSA-B, AND MOSA-C CONFIGURATIONS)

\begin{tabular}{|c|c|c|c|}
\hline & $k_{\text {MOSAF }}$ & $N_{\text {MOSAF }} / N_{\text {tot }}$ & $\begin{array}{c}\text { MOSAFR } \\
\text { (failures/100 km-year) }\end{array}$ \\
\hline $\begin{array}{c}\text { Stretch 1 } \\
\text { (MOSA-A) }\end{array}$ & 0.6 & 0.1075 & 0.213 \\
\hline $\begin{array}{c}\text { Stretch 2 } \\
\text { (MOSA-A) }\end{array}$ & 0.6 & 0.3741 & 0.044 \\
\hline $\begin{array}{c}\text { Stretch 1 } \\
\text { (MOSA-B) }\end{array}$ & 0.6 & 0.1460 & 0.290 \\
\hline $\begin{array}{c}\text { Stretch 2 } \\
\text { (MOSA-B) }\end{array}$ & 0.6 & 0.508 & 0.059 \\
\hline $\begin{array}{c}\text { Stretch 1 } \\
\text { (MOSA-C) }\end{array}$ & 0.6 & 0.1500 & 0.298 \\
\hline $\begin{array}{c}\text { Stretch 2 } \\
\text { (MOSA-C) }\end{array}$ & 0.6 & 0.5220 & 0.061 \\
\hline
\end{tabular}

366 Tables XI and XII report the BFORs and MOSAFRs obtained 367 considering MOSA-A, MOSA-B, and MOSA-C configura368 tions, respectively.

369 With regard to BFOR reduction, MOSA-C (MOSAs installed 370 only on lower phase) is the most effective configuration (a $46.4 \%$ 371 reduction with respect to the Base Case), whereas in terms 372 of MOSAFR, the MOSA-A configuration yields the best re373 sults $(0.257$ failures $/ 100 \mathrm{~km} / \mathrm{year}$, corresponding to 0.028 fail374 ures/year, i.e., a MOSA failure every 36 years).

\section{D. Comparison Between Countermeasures}

376 With regard to BFOR reduction, the best solution is the 377 MOSA-ABC configuration of Countermeasure 2, which alto378 gether suppresses back flashovers and only introduces a negli379 gible MOSA failure rate (a failure every 22.7 years). However, this countermeasure is also relatively expensive, since it re- 380 quires the installation of 114 MOSAs, i.e., $10.7 \mathrm{MOSAs} / \mathrm{km} . \quad 381$

The MOSA-C configuration (arresters on the lower phase) 382 practically halves the original BFOR, at one third of the ar- 383 resters' procurement cost (around $2 \mathrm{k} / \mathrm{mnit}$ for bulk purchases). 384

Installation costs of Countermeasure 2 can be estimated 385 as follows, assuming use of internal workforce (workforce is 386 deployed in four-man squads, with a conventional cost of $35+387$ man-hour):

- MOSA-C: (4 $\mathrm{h}$ to reach the tower $+2.5 \mathrm{~h}$ to install one 390 MOSA $) \times 4=26$ man-hours $=910 € /$ tower; total cost for 391 38 towers is $110.58 \mathrm{k} €$;

- MOSA-ABC: $(4 \mathrm{~h}$ to reach the tower $+4 \mathrm{~h}$ to install three 393 MOSAs) $\times 4=32$ man-hours $=1120 € /$ tower; total cost 394 for 38 towers is $270.56 \mathrm{k} €$ (it can be readily seen that 395 labor cost is a fraction of MOSA cost).

Countermeasure 1 seems to be the most effective one from a 397 technical-economic point of view, yielding BFOR values com- 398 parable with those of the MOSA-C configuration. Attendant 399 civil works only involve the existing pylon base area, thus min- 400 imizing the authorization and property expropriation problems 401 related to the substitution of the old grounding systems along 402 the line. The cost of Countermeasure 1 strongly depends on 403 tower location and soil hardness. In case of soft soil, costs are 404 expected to be significantly lower than for Countermeasure 2. 405 Considering 600 tower for the grounding rods and 30 man- 406 hours per tower, the cost of Countermeasure 1 is $1.65 \mathrm{k} /$ tower, 407 i.e., $62.7 \mathrm{k}$ total. Hard soil requires a vertical drilling rig, 408 which must be leased and then, at inaccessible tower sites, also 409 delivered by helicopter. The additional costs involved can be 410 roughly estimated at 1500 tower raising the total to $119.7 \mathrm{k}$ : in 411 such cases, MOSA-C Countermeasure 2 becomes competitive. 412

\section{CONCLUSION}

The analysis of remedial measures aimed at reducing the 414 exceptionally high BFOR ( 70 faults $/ 100 \mathrm{~km} /$ year) of an existing 415 10.8-km-long $150-\mathrm{kV}$ OHL has been carried out by means of a 416 Monte Carlo procedure, based on detailed ATP-EMTP transient 417 simulations. The proposed remedial measures are as follows: 418

1) reduction of tower grounding low-frequency resistances 420 by installing additional vertical grounding rods; 421

2) installation of MOSAs across the insulation of one or all 422 phases (line arresters).

423

The extensive statistically based ATP-EMTP transient analy- 424 sis evidenced the following main results. 425

426

- The installation of MOSAs across all phases is the tech- 427 nical best, as it suppresses the BFOR, with a fairly low 428 MOSA failure rate (a failure every 22.7 years). The capital 429 cost of the 114 line arresters is, however, significant. $\quad 430$

- The installation of only one arrester per tower yields a sig- 431 nificant BFOR reduction at a lower capital cost; the most 432 effective location is the lower phase (BFOR is 34.2 faults/ 433 $100 \mathrm{~km} /$ year). 
As an additional remark, the study showed the applicability 444 of the authors' ATP-EMTP Monte Carlo procedure to a practi445 cal problem.

- The installation at each tower of four additional vertical grounding rods, each $5 \mathrm{~m}$ long, is comparable with the use of one MOSA per tower (lower phase), with a calculated BFOR equal to 31.6 faults $/ 100 \mathrm{~km} /$ year; its economic convenience, however, depends on accessibility, as well as soil hardness, of the tower foot. An economic analysis thus requires taking into account the exact location of each tower.
REFERENCES

1] S. Rajan and S. I. Venugopalan, "Corrosion and grounding systems," IEEE Trans. Ind. Appl., vol. IA-13, no. 4, pp. 297-306, Jul./Aug. 1977.

2] J. He, R. Zeng, J. Hu, S. M. Chen, and J. Zhao, "Design and application of line surge arresters to improve lightning protection characteristics of transmission lines," in Proc. IEEE Power Eng. Soc. Transmiss. Distrib. Conf., 2008, pp. 1-8.

3] S. Furukawa, O. Usuda, T. Isozaki, and T. Irie, "Development and application of lightning arresters for transmission lines," IEEE Trans. Power Del., vol. 4, no. 4, pp. 2121-2129, Oct. 1989.

4] L. M. Mswane and C. T. Gaunt, "Lightning performance improvement of the Swaziland electricity board transmission system $(66 \mathrm{kV} \& 132 \mathrm{kV}$ lines)—Results of the pilot project," in Proc. IEEE Power Eng. Soc. Inaugural Conf. Expo., 2005, pp. 364-370.

5] K. Munukutla, V. Vittal, G. T. Heydt, D. Chipman, and B. Keel, “A practical evaluation of surge arrester placement for transmission line lightning protection," IEEE Trans. Power Del., vol. 25, no. 3, pp. 1742-1748, Jul. 2010.

[6] S. Bedoui, A. Bayadi, and A. M. Haddad, "Analysis of lightning protection with transmission line arrester using ATP/EMTP: Case of an HV 220 kV double circuit line," in Proc. UPEC, 2010, pp. 1-6.

7] J. A. Martinez and F. Castro-Aranda, "Lightning flashover rate of an overhead transmission line protected by surge arresters," in Proc. IEEE Power Eng. Soc. Gen. Meet., 2007, pp. 1-6.

8] R. Shariatinasab, F. Ajri, and H. Daman-Khorshid, "Probabilistic evaluation of failure risk of transmission line surge arresters caused by lightning flash," IET Gen., Transmiss. Distrib., vol. 8, no. 2, pp. 193-202, Feb. 2014.

[9] F. M. Gatta, A. Geri, S. Lauria, M. Maccioni, and A. Santarpia, "An ATPEMTP Monte Carlo procedure for backflashover rate evaluation," in Proc. ICLP, 2012, pp. 1-6.

0] F. M. Gatta, A. Geri, S. Lauria, M. Maccioni, and A. Santarpia, "An ATP-EMTP Monte Carlo procedure for backflashover rate evaluation: A comparison with the CIGRE method," Elect. Power Syst. Res., vol. 113, pp. 134-140, Aug. 2014

1] F. M. Gatta, A. Geri, S. Lauria, and M. Maccioni, "Equivalent lumped parameter $\pi$-network of typical tower grounding systems for linear and nonlinear transient analyses," in Proc. IEEE PowerTech Conf., 2009, pp. 1-6.

2] F. M. Gatta, A. Geri, S. Lauria, and M. Maccioni, "Simplified HV tower grounding system model for backflashover simulation," in Proc. ICLP, 2010, pp. 1-6.

3] F. M. Gatta, A. Geri, S. Lauria, and M. Maccioni, "Simplified HV tower grounding system model for backflashover simulation," Elect. Power Syst. Res., vol. 85, pp. 16-23, Apr. 2012.

4] A. Geri, "Behavior of grounding systems excited by high impulse currents: The model and its validation," IEEE Trans. Power Del., vol. 14, no. 3, pp. 1008-1017, Jul. 1999.

5] D. L. Carroll, FORTRAN Genetic Algorithm (GA) Driver. [Online]. Available: http://cuaerospace.com/carroll/ga.html

6] Alternative Transients Program (ATP) Rule Book, Canadian/American EMTP User Group, Linn, OR, USA, 1995.

7] P. Pinceti and M. Giannettoni, "A simplified model for zinc oxide surge arresters," IEEE Trans. Power Del., vol. 14, no. 2, pp. 393-398, Apr. 1999.

IEEE Working Group 3.4.11, "Modeling of metal oxide surge arresters," IEEE Trans. Power Del., vol. 7, no. 1, pp. 302-309, Jan. 1992.

19] C. A. Christodoulou, F. A. Assimakopoulou, I. F. Gonos, and I. A. Stathopulos, "Simulation of metal oxide surge arresters behavior," in Proc. IEEE Power Electron. Spec. Conf., 2008, pp. 1862-1866.

20] Surge Arresters - Part 4: Metal-Oxide Surge Arresters Without Gaps for A.C. Systems, IEC 60099-4 ed. 3.0, Jun. 2014.
[21] A. J. Eriksson, "An improved electrogeometric model for transmis- 505 sion line shielding analysis," IEEE Trans. Power Del., vol. 2, no. 3, 506 pp. 871-886, Jul. 1987.

[22] A. R. Hileman, Insulation Coordination for Power Systems. New York, 508 NY, USA: Marcel Dekker, 1999.

[23] CIGRE Working Group 01 of SC 33, "Guide to Procedures for Estimating 510 the Lightning Performance of Transmission Lines," GRE Brochure no. 63, 511 Oct. 1991.

[24] Lightning and Insulator Subcommittee of the T\&D Committee, "Param- 513 eters of lightning strokes: A review," IEEE Trans. Power Del., vol. 20, 514 no. 1, pp. 346-358, Jan. 2005.

[25] J. A. Martinez and F. Castro-Aranda, "Lightning performance analysis of 516 overhead transmission lines using the EMTP," IEEE Trans. Power Del., 517 vol. 20, no. 3, pp. 2200-2210, Jul. 2005.

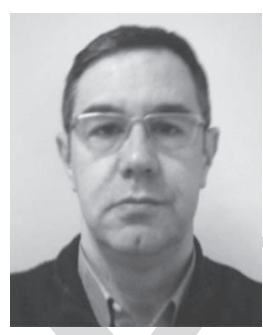

Fabio Massimo Gatta was born in Alatri, Italy, 519 in 1956. He received the M.Sc.(Hons.) degree in 520 electrical engineering from the University of Rome 521 "La Sapienza," Rome, Italy, in 1981. He then joined the Department of Astronautics, 523 Electrical and Energy Engineering of the University 524 of Rome "La Sapienza," where he became a Re- 525 searcher in 1985 and was appointed an Associate 526 Professor of electrical power systems in 1998. His 527 main research interests are in the field of power sys- 528 tem analysis; long-distance transmission; transient 529 stability; temporary and transient overvoltages; series and shunt compensation; 530 SSR; distributed generation; power plants; design, planning; and operation 531 of transmission and distribution networks; - and unconventional distribution 532 systems.

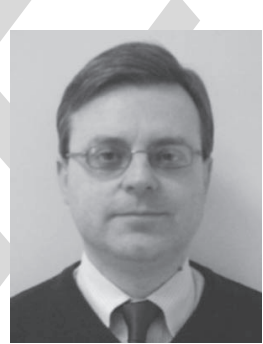

Alberto Geri was born in Terni, Italy, on August 534 4, 1961. He received the M.Sc. degree in elec- 535 trical engineering from the University of Rome 536 "La Sapienza," Rome, Italy, in 1987.

He began his academic activity in 1989 as a 538 Researcher of Electrical Science with the University 539 of Rome "La Sapienza," where he was an Asso- 540 ciate Professor of electrical engineering from 2000541 to 2015 and has been an Associate Professor of 542 electrical power systems since 2015 . He has been a 543 recipient of many research contracts and grants from 544 institutional sources and private investors. He began his research activity in 545 1982. He has authored or coauthored over 150 papers presented at international 546 conferences or published in peer-reviewed international journals. His interests 547 include direct electrical energy conversion by magnetohydrodynamics devices, 548 renewable energy conversion and bioremediation by microbial fuel cells, low- 549 frequency electric and magnetic field computation, high-frequency magnetic 550 device modeling, nonlinear electromagnetic problems in power systems related 551 to lightning, medium-voltage/low-voltage distribution networks, distributed 552 generation, and smart and micro grids.

Prof. Geri is a corresponding member of the International Council on Large 554 Electric Systems (CIGRÉ) Working Group C4.406 "Performance of Grounding 555 Electrodes for Lightning Currents."

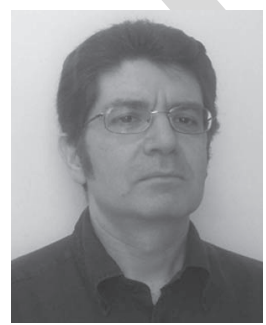

Stefano Lauria (M'98) was born in Rome, Italy, 557 in 1969. He received the M.Sc. and Ph.D. degrees 558 in electrical engineering from the University of 559 Rome "La Sapienza," Rome, in 1996 and 2001, 560 respectively.

In 2000, he joined the Department of Astronau- 562 tics, Electrical and Energy Engineering of the Uni- 563 versity of Rome "La Sapienza" as a Researcher. His 564 research interests include power systems analysis, 565 distributed generation, $\mathrm{HV}$ and extra $\mathrm{HV}$ ac cable 566 transmission, shunt compensation, and electromag- 567 netic transients. He has authored or coauthored over 85 papers presented at 568 international conferences or published in peer-reviewed international journals. 569

Dr. Lauria is a member of the International Council on Large Electric 570 Systems (CIGRÉ) and the IEEE Power and Energy Society. 


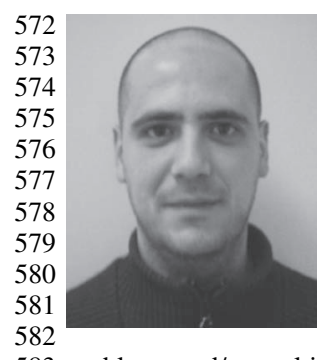

Marco Maccioni was born in Anagni, Italy, on June 24, 1978. He received the M.Sc. and Ph.D. degrees in electrical engineering from the University of Rome "La Sapienza," Rome, Italy, in 2005 and 2010, respectively.

He is currently with the Department of Astronautics, Electrical and Energetics Engineering of the University of Rome "La Sapienza" on a research grant. His main interests include power system analysis, evolutionary algorithms implemented on parallel architectures and applied to solve synthesis 583 problems and/or multiobjective optimization problems, smart grids, and non584 linear electromagnetic problems related to lightning.

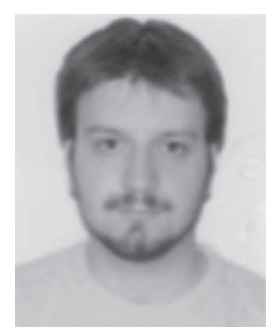

Francesco Palone was born in Rome, Italy, in 1985. 585 He received the B.Sc., M.Sc., and Ph.D. degrees 586 from the University of Rome "La Sapienza," Rome, 587 Italy, in 2007, 2009, and 2013, respectively, all in 588 electrical engineering.

589

In 2009, he joined the Engineering Department, 590

Terna, Rome, the Italian transmission system oper- 591 ator and network owner, engaging in electromag- 592 netic transient studies, transformer specification, and 593 battery energy storage design. Since 2012, he has 594 been with Terna Rete Italia S.p.A, Rome. His fields 595 of research are cable and transformer modeling for time- and frequency- 596 domain studies, compensation apparatus (reactors, phase-shifting transformers, 597 synchronous condensers), and interconnection lines. 


\section{AUTHOR QUERIES}

\section{AUTHOR PLEASE ANSWER ALL QUERIES}

AQ1 = ACSR was expanded as "aluminium conductor steel reinforced." Please check if appropriate. Otherwise, please provide the corresponding expanded form.

AQ2 = The value " $1 \mathrm{~Hz} \div 1 \mathrm{MHz}$ " was changed to "1 Hz to $1 \mathrm{MHz}$." Please check if appropriate. Otherwise, please make the necessary changes.

AQ3 = Please provide the expanded form of "SSR."

\section{END OF ALL QUERIES}

